\title{
Comparison of the Effect of Preinterventional Arterial Remodeling on Intimal Hyperplasia after Implantation of a Sirolimus- or Paclitaxel-Eluting Stent
}

\author{
Woong Chol Kang ${ }^{\mathrm{a}}$ Taehoon Ahn $^{\mathrm{a}}$ Chan II Moon ${ }^{\mathrm{a}}$ Kyunghoon Lee $^{\mathrm{a}}$ \\ Seung Hwan Han ${ }^{a}$ Eak Kyun Shin ${ }^{a}$ Jung-Sun Kim ${ }^{b}$ Young-Guk Ko ${ }^{b}$ \\ Donghoon Choi ${ }^{\mathrm{b}}$ Yangsoo Jang ${ }^{\mathrm{b}}$ Byoung-Keuk Kim ${ }^{c}$ Seong Jin Oh ${ }^{c}$ \\ Dong Woon Jeon ${ }^{c}$ Joo-Young Yang ${ }^{c}$ \\ a Division of Cardiology, Gachon University of Medicine and Science, Incheon, b Division of Cardiology, \\ Yonsei University College of Medicine, Seoul, and ' NHIC Ilsan Hospital, Koyang, Korea
}

\section{Key Words}

Arterial remodeling $\cdot$ Remodeling index .

Drug-eluting stent $\cdot$ Intimal hyperplasia

\begin{abstract}
Background: We compared the effect of arterial remodeling on intimal hyperplasia $(I H)$ after the implantation of a sirolimus-eluting stent (SES) and a paclitaxel-eluting stent (PES). Methods: The study population consisted of patients with positive or intermediate remodeling and negative remodeling. Results: Sixty-nine patients had positive or intermediate remodeling and 107 patients had negative remodeling. At follow-up, late loss was significantly larger $(0.58 \pm 0.65$ vs. $0.38 \pm 0.55 \mathrm{~mm} ; \mathrm{p}=0.026)$ in the patients with positive or intermediate remodeling. The $\mathrm{IH}$ volume $(22.6 \pm 26.2 \mathrm{vs}$. $\left.12.4 \pm 17.4 \mathrm{~mm}^{3} ; \mathrm{p}=0.002\right)$ and the percent $\mathrm{IH}(12.9 \pm 14.8$ vs. $7.0 \pm 9.6 \% ; p=0.002$ ) were significantly higher in the $p a-$ tients with positive or intermediate remodeling. Compared to negative remodeling, the $\mathrm{IH}$ volume was higher in the PES patients with positive or intermediate remodeling, but this difference was not noted in the SES patients. Multiple-regression analysis revealed that arterial remodeling was a significant independent variable for predicting $\mathrm{IH}$ volume in
\end{abstract}

\section{KARGER}

Fax +41613061234 E-Mail karger@karger.ch www.karger.com (c) 2010 S. Karger AG, Basel

$0008-6312 / 10 / 1162-0117 \$ 26.00 / 0$

Accessible online at:

www.karger.com/crd the PES patients $(p=0.018)$. A positive correlation was found between the remodeling index and the $\mathrm{IH}$ volume in the PES patients $(r=0.234, p=0.028)$, but not in the SES patients. Conclusions: This prospective observational intravascular ultrasound study showed that drug-eluting stents may have a different effect on reducing $\mathrm{IH}$ accumulation in lesions with preinterventional positive remodeling characteristics which may be related to the different properties of the drug and delivery platform.

Copyright $\odot 2010$ S. Karger AG, Basel

\section{Introduction}

Drug-eluting stents (DESs) with antiproliferative and antimigratory properties appear to be clinically efficacious in inhibiting restenosis via an inhibitory effect on smooth muscle cells. However, different drug mechanisms and delivery platforms may translate into different clinical efficacies. Although previous intravascular ultrasound (IVUS) studies have shown that positive preinterventional arterial remodeling is associated with increased intimal hyperplasia (IH), a higher restenosis and/or target lesion revascularization rate, and a worse clinical out-

Tae Hoon Ahn, MD

Cardiology, Gil Medical Center, Gachon University of Medicine and Science

1198 Kuwol-dong

Namdong-gu, Incheon 405-760 (Korea)

Tel. +82 32460 3046/3674, Fax +82 32460 3117, E-Mail kangwch@ gilhospital.com 
come, these relationships need clarification in the DES era [1-6]. We investigated and compared the effect of preinterventional arterial remodeling (positive or intermediate remodeling and negative remodeling) on IH after the implantation of two different DESs: the sirolimuseluting stent (SES, Cypher; Cordis, Miami, Fla., USA) and the paclitaxel-eluting stent (PES, Taxus; Boston Scientific, Natick, Mass., USA).

\section{Methods}

\section{Study Design and Patient Population}

This study was a multicenter, prospective observational study. Three hundred and one consecutive patients were screened from May 2005 through June 2007. The patients underwent percutaneous coronary interventions with a DES at a de novo stenosis of a native coronary artery in a reference vessel between 2.5 and 3.5 $\mathrm{mm}$ in diameter that could be covered by a single stent (defined as a decrease of $\geq 70 \%$ in the luminal diameter in a major epicardial coronary artery). After an IVUS, the lesions were excluded when (1) intimal calcification at the target lesion was so severe that it precluded accurate quantification of the IVUS imaging, (2) an IVUS study of the target lesion and reference segments could not be performed before the subsequent intervention, (3) there were major side branches between the proximal and distal reference segments, or (4) a distinct dissection was made at the stent edge after stenting. Finally, 176 patients were enrolled into this study. The primary outcomes were the $\mathrm{IH}$ volume and percent $\mathrm{IH}$ (IH volume/lumen volume, \%IH) at follow-up. The study was approved by our Institutional Review Board and all patients gave their written informed consent.

\section{Procedure}

The percutaneous coronary interventions were performed with 6- or 7-french guiding catheters and conventional techniques. An IVUS study was performed in all patients prior to the intervention. The stent diameter was selected based on the preinterventional IVUS measurements (with a ratio of the stent balloon diameter to the reference diameter of 1.1:1.0). Stents were selected before angioplasty using a computer-generated random allocation. The stents were initially implanted with a nominal pressure inflation using a stent delivery balloon. An inflation time of $10 \mathrm{~s}$ was required. After stenting, angiographic and IVUS assessments were performed to assess the success of the deployment or the need for additional balloon inflation. Before the percutaneous coronary intervention, $200 \mathrm{mg}$ of aspirin was administered orally, followed by oral administration of $100 \mathrm{mg}$ /day. In addition to the aspirin, a 300-mg loading dose of clopidogrel was given and a maintenance dosage of $75 \mathrm{mg} /$ day was recommended for 3-12 months. Antithrombotic regimens, including intravenous heparin and glycoprotein IIb/IIIa inhibitors, were used at the discretion of the treating physicians. Follow-up angiographic and IVUS examinations were performed at 9 months after the index procedure. Clinical follow-up was also performed at 1 and 9 months after the index procedure.
Angiographic Data Analysis

Quantitative coronary angiography was performed using an off-line system (CMS; Medis Medical Imaging Systems, Nuenen, The Netherlands) by a single individual who was blinded to the patient's treatment assignment. The minimal luminal diameter of the treated coronary segments, reference diameter, percent diameter stenosis, and lesion length on the baseline angiogram were determined in the view that demonstrated the lesion to be the most severe and not foreshortened. Angiographic success was defined as a Thrombolysis In Myocardial Infarction (TIMI) flow grade of 3 and $a<20 \%$ residual stenosis diameter by visual assessment. Restenosis was defined as a $>50 \%$ stenosis diameter determined by quantitative coronary angiography within a previously stented segment.

\section{IVUS Assessment}

An IVUS assessment was performed using a commercially available IVUS system (Boston Scientific/Scimed, Natick, Mass., USA). The studies were recorded on an s-VHS tape and an Index system (Echoplaque 2; INDEC Systems Inc., Mountain View, Calif., USA) for off-line analysis. A motorized transducer pullback permitted cross-sectional area (CSA) measurements at $0.5 \mathrm{~mm}$ axial increments throughout the length of the stent. All IVUS studies were performed after the intracoronary administration of $200 \mu \mathrm{g}$ of nitroglycerin. The reference segment was the visually most normal cross-section (largest lumen with the least plaque burden) within $10 \mathrm{~mm}$ proximal or distal to the lesion. Using the software, the external elastic membrane (EEM) CSA, lumen CSA, minimal stent cross-sectional area, identified as the CSA at the tightest segment within the stent, and stent minimal luminal diameter were determined. The CSA at the proximal and distal reference segments and at the most stenotic lesion as well as the CSA at the proximal and distal stent edges was determined. A volumetric IVUS analysis was also performed. Using computerized planimetry, the postintervention and follow-up vessel, stent, lumen, and $\mathrm{IH}$ (stent minus lumen) areas were measured every $1 \mathrm{~mm}$ within the stented segment and at both edge segments. The volumes were calculated using Simpson's rule. The remodeling index (RI) was also defined as follows: the target lesion EEM CSA divided by the average of the proximal and distal reference EEM CSAs. The three subgroups were defined as positive remodeling ( $\mathrm{RI} \geq 1.05)$, intermediate remodeling $(0.95 \leq \mathrm{RI}<1.05)$, or negative remodeling $(\mathrm{RI}<0.95)$ [7].

\section{Statistical Analysis}

The values were expressed as means \pm SD. The patient demographics, clinical history, risk factors, and procedure data were summarized using descriptive statistics for continuous variables and frequency tables or proportions for discrete variables. The continuous variables were compared with an analysis of variance. The categorical variables were expressed as frequencies and compared using $\chi^{2}$ statistics or a Fisher's exact test. A simple regression analysis was used to find the correlation between the baseline $\mathrm{RI}$ and IH volume at follow-up. A multivariate logistic regression analysis was undertaken to identify any independent predictors of IH. All statistical analyses were performed with SPSS 13.0 software (SPSS, Inc., Chicago, Ill., USA). p $<0.05$ was considered statistically significant. 


\section{Results}

\section{Baseline Characteristics}

Of the 176 patients enrolled in this study, 69 patients had positive or intermediate remodeling and $107 \mathrm{had}$ negative remodeling. All the clinical baseline characteristics of the study population are presented in table 1. There was no statistically significant difference in the clinical characteristics except for hypertension, which was more common in the group with negative remodeling.

\section{Angiographic Results}

The results of quantitative coronary angiography are summarized in table 2 . There was no significant difference in the reference vessel diameter, lesion length, diameter stenosis or minimal lumen diameter at baseline or after the percutaneous coronary intervention between the two groups. At follow-up, the late loss was significantly larger $(0.58 \pm 0.65$ vs. $0.38 \pm 0.55 \mathrm{~mm} ; \mathrm{p}=0.026)$ and restenosis rate higher $(13.0$ vs. $3.7 \%$; $=0.036)$ in the group with positive or intermediate remodeling than in the group with negative remodeling. All restenoses were observed in the PES patients.

\section{IVUS Results}

The IVUS results for all patients are shown in table 3. The RI was $1.12 \pm 0.16$ in the group with positive or intermediate remodeling and $0.75 \pm 0.12$ in the group with negative remodeling $(\mathrm{p}=0.000)$. There was no significant difference between the two groups in the lumen CSA at the minimal lesion site prior to $(2.04 \pm 1.04$ vs. $1.97 \pm$ $\left.0.86 \mathrm{~mm}^{2} ; \mathrm{p}=0.625\right)$ or after stenting $(7.77 \pm 2.46 \mathrm{vs} .7 .67$ $\left.\pm 2.34 \mathrm{~mm}^{2} ; \mathrm{p}=0.788\right)$. At 9 months of follow-up although the lumen volume did not differ between the two groups $\left(166.4 \pm 67.6\right.$ vs. $\left.168.9 \pm 60.0 \mathrm{~mm}^{3} ; \mathrm{p}=0.797\right)$ the $\mathrm{IH}$ volume was significantly higher in the group with positive or intermediate remodeling (22.6 \pm 26.2 vs. 12.4 $\left.\pm 17.4 \mathrm{~mm}^{3} ; \mathrm{p}=0.002\right)$. Further, \%IH was also higher in the group with positive or intermediate remodeling than in the group with negative remodeling $(12.9 \pm 14.8$ vs. $7.0 \pm 9.6 \% ; \mathrm{p}=0.002$ ). In the analysis of the SES patients, there were no significant differences in the IH volume or $\% \mathrm{IH}$ at follow-up between the two groups (table 4). Conversely, both the IH volume and \% IH were higher in the group with positive or intermediate remodeling than in the group with negative remodeling among the PES patients (table 5). A multiple regression analysis including the pattern of remodeling, hypertension, diabetes, stent diameter and length revealed that the pattern of the arte-
Table 1. Baseline clinical characteristics (all)

\begin{tabular}{lccc}
\hline & PR/IR $(\mathrm{n}=69)$ & $\mathrm{NR}(\mathrm{n}=107)$ & $\mathrm{p}$ value \\
\hline Age, years & $62.3 \pm 9.5$ & $61.7 \pm 9.2$ & 0.770 \\
Men & $40(58.0)$ & $62(27.9)$ & 1.000 \\
Risk factors & & & \\
$\quad$ Smoking & $18(26.1)$ & $22(20.6)$ & 0.518 \\
$\quad$ Diabetes & $25(36.2)$ & $31(29.0)$ & 0.325 \\
$\quad$ Hypertension & $38(55.1)$ & $77(72.0)$ & 0.032 \\
$\quad$ Dyslipidemia & $14(20.3)$ & $25(23.4)$ & 0.710 \\
$\quad$ Prior MI & $2(2.9)$ & $9(8.4)$ & 0.204 \\
$\quad$ Prior PCI & $4(5.8)$ & $16(15.0)$ & 0.087 \\
LVEF, \% & $55.6 \pm 13.4$ & $56.5 \pm 5.2$ & 0.762 \\
Diagnosis & & & 0.008 \\
$\quad$ Stable AP & $28(40.6)$ & $66(61.7)$ & \\
$\quad$ Unstable AP & $41(59.4)$ & $41(38.3)$ & \\
\hline
\end{tabular}

Figures in parentheses are percentages. $\mathrm{PR} / \mathrm{IR}=$ Positive or intermediate remodeling; $\mathrm{NR}=$ negative remodeling; $\mathrm{AP}=$ angina pectoris; $\mathrm{LVEF}=$ left ventricular ejection fraction; $\mathrm{MI}=$ myocardial infarction; $\mathrm{PCI}=$ percutaneous coronary intervention.

Table 2. Quantitative coronary angiographic results (all)

\begin{tabular}{|c|c|c|c|}
\hline & $\begin{array}{l}\mathrm{PR} / \mathrm{IR} \\
(\mathrm{n}=69)\end{array}$ & $\begin{array}{l}\text { NR } \\
(n=107)\end{array}$ & $\begin{array}{l}\mathrm{p} \\
\text { value }\end{array}$ \\
\hline \multicolumn{4}{|l|}{ Before the intervention } \\
\hline Lesion length, $\mathrm{mm}$ & $20.8 \pm 6.6$ & $20.4 \pm 6.7$ & 0.689 \\
\hline $\mathrm{RVD}, \mathrm{mm}$ & $3.00 \pm 0.39$ & $3.04 \pm 0.45$ & 0.583 \\
\hline MLD, mm & $0.65 \pm 0.48$ & $0.60 \pm 0.49$ & 0.405 \\
\hline DS, $\%$ & $69.2 \pm 16.8$ & $67.1 \pm 16.0$ & 0.408 \\
\hline \multicolumn{4}{|l|}{ After the intervention } \\
\hline Stent diameter, $\mathrm{mm}$ & $3.23 \pm 0.30$ & $3.23 \pm 0.29$ & 0.909 \\
\hline Stent length, mm & $24.5 \pm 5.4$ & $23.7 \pm 5.5$ & 0.369 \\
\hline Stent pressure, atm & $10.5 \pm 2.0$ & $10.8 \pm 2.0$ & 0.345 \\
\hline Post-stent pressure, atm & $19.1 \pm 2.4$ & $18.7 \pm 1.7$ & 0.249 \\
\hline MLD, $\mathrm{mm}$ & $2.92 \pm 0.38$ & $2.98 \pm 0.37$ & 0.342 \\
\hline DS, \% & $14.0 \pm 10.2$ & $13.6 \pm 9.6$ & 0.875 \\
\hline \multicolumn{4}{|l|}{ Follow-up } \\
\hline MLD, mm & $2.34 \pm 0.75$ & $2.60 \pm 0.55$ & 0.010 \\
\hline DS, \% & $19.2 \pm 22.8$ & $11.2 \pm 16.5$ & 0.008 \\
\hline Late lumen loss, $\mathrm{mm}$ & $0.58 \pm 0.65$ & $0.38 \pm 0.55$ & 0.026 \\
\hline Restenosis & $9 / 69(13.0 \%)$ & $4 / 107(3.7 \%)$ & 0.036 \\
\hline
\end{tabular}

$\mathrm{PR} / \mathrm{IR}=$ Positive or intermediate remodeling; $\mathrm{NR}=$ negative remodeling; RVD = reference vessel diameter; MLD = minimal luminal diameter; $\mathrm{DS}=$ diameter stenosis. 
Table 3. Quantitative intravascular ultrasound results (all)

\begin{tabular}{|c|c|c|c|}
\hline & $\begin{array}{l}\mathrm{PR} / \mathrm{IR} \\
(\mathrm{n}=69)\end{array}$ & $\begin{array}{l}\text { NR } \\
(n=107)\end{array}$ & $\begin{array}{l}\mathrm{p} \\
\text { value }\end{array}$ \\
\hline \multicolumn{4}{|l|}{ Before the intervention } \\
\hline \multicolumn{4}{|l|}{ Proximal reference } \\
\hline EEM CSA, mm² & $13.39 \pm 4.25$ & $14.26 \pm 4.34$ & 0.195 \\
\hline \multicolumn{4}{|l|}{ Lesion segment } \\
\hline EEM CSA, mm² & $12.77 \pm 4.75$ & $9.39 \pm 3.34$ & 0.000 \\
\hline Lumen CSA, mm ${ }^{2}$ & $2.04 \pm 1.04$ & $1.97 \pm 0.86$ & 0.625 \\
\hline $\mathrm{P}+\mathrm{M}$ CSA, $\mathrm{mm}^{2}$ & $10.63 \pm 4.56$ & $7.43 \pm 3.18$ & 0.000 \\
\hline RI & $1.12 \pm 0.16$ & $0.75 \pm 0.12$ & 0.000 \\
\hline \multicolumn{4}{|l|}{ Distal reference } \\
\hline EEM CSA, mm ${ }^{2}$ & $10.41 \pm 4.10$ & $10.54 \pm 3.95$ & 0.841 \\
\hline \multicolumn{4}{|l|}{ After the intervention } \\
\hline Minimal stent CSA, $\mathrm{mm}^{2}$ & $7.77 \pm 2.46$ & $7.67 \pm 2.34$ & 0.788 \\
\hline Symmetry index & $1.07 \pm 0.56$ & $1.09 \pm 0.68$ & 0.256 \\
\hline \multicolumn{4}{|l|}{ Follow-up } \\
\hline Lumen volume, $\mathrm{mm}^{3}$ & $166.4 \pm 67.6$ & $168.9 \pm 60.0$ & 0.797 \\
\hline IH volume, $\mathrm{mm}^{3}$ & $22.6 \pm 26.2$ & $12.4 \pm 17.4$ & 0.002 \\
\hline$\% \mathrm{IH}$ & $12.9 \pm 14.8$ & $7.0 \pm 9.6$ & 0.002 \\
\hline
\end{tabular}

$\mathrm{PR} / \mathrm{IR}=$ Positive or intermediate remodeling; $\mathrm{NR}=$ negative remodeling; $\mathrm{P}+\mathrm{M}=$ plaque plus media.

Table 4. Quantitative IVUS results for SES implantations

\begin{tabular}{|c|c|c|c|}
\hline & $\begin{array}{l}\mathrm{PR} / \mathrm{IR} \\
(\mathrm{n}=27)\end{array}$ & $\begin{array}{l}\text { NR } \\
(n=53)\end{array}$ & $\begin{array}{l}\mathrm{p} \\
\text { value }\end{array}$ \\
\hline \multicolumn{4}{|l|}{ Before the intervention } \\
\hline \multicolumn{4}{|l|}{ Proximal reference } \\
\hline EEM CSA, $\mathrm{mm}^{2}$ & $12.92 \pm 2.55$ & $14.31 \pm 4.57$ & 0.148 \\
\hline \multicolumn{4}{|l|}{ Lesion segment } \\
\hline EEM CSA, mm² & $12.41 \pm 3.29$ & $9.36 \pm 3.42$ & 0.000 \\
\hline Lumen CSA, $\mathrm{mm}^{2}$ & $2.28 \pm 1.17$ & $2.08 \pm 0.75$ & 0.346 \\
\hline $\mathrm{P}+\mathrm{M}$ CSA, $\mathrm{mm}^{2}$ & $10.14 \pm 3.07$ & $7.28 \pm 3.27$ & 0.000 \\
\hline RI & $1.12 \pm 0.14$ & $0.75 \pm 0.11$ & 0.000 \\
\hline \multicolumn{4}{|l|}{ Distal reference } \\
\hline EEM CSA, mm² & $9.47 \pm 2.59$ & $10.45 \pm 4.13$ & 0.261 \\
\hline \multicolumn{4}{|l|}{ After the intervention } \\
\hline Minimal stent CSA, $\mathrm{mm}^{2}$ & $7.29 \pm 1.60$ & $7.11 \pm 1.59$ & 0.645 \\
\hline Symmetry index & $1.06 \pm 0.63$ & $1.07 \pm 0.59$ & 0.483 \\
\hline \multicolumn{4}{|l|}{ Follow-up } \\
\hline Lumen volume, $\mathrm{mm}^{3}$ & $175.0 \pm 73.3$ & $166.2 \pm 53.8$ & 0.797 \\
\hline IH volume, $\mathrm{mm}^{3}$ & $5.8 \pm 10.4$ & $3.8 \pm 6.2$ & 0.287 \\
\hline$\% \mathrm{IH}$ & $3.8 \pm 7.1$ & $2.5 \pm 4.1$ & 0.272 \\
\hline
\end{tabular}

$\mathrm{PR} / \mathrm{IR}=$ Positive or intermediate remodeling; $\mathrm{NR}=$ negative remodeling; $\mathrm{P}+\mathrm{M}=$ plaque plus media.
Table 5. Quantitative IVUS for PES implantations

\begin{tabular}{|c|c|c|c|}
\hline & $\begin{array}{l}\mathrm{PR} / \mathrm{IR} \\
(\mathrm{n}=42)\end{array}$ & $\begin{array}{l}\text { NR } \\
(\mathrm{n}=54)\end{array}$ & $\begin{array}{l}\mathrm{p} \\
\text { value }\end{array}$ \\
\hline \multicolumn{4}{|l|}{ Before the intervention } \\
\hline \multicolumn{4}{|l|}{ Proximal reference } \\
\hline EEM CSA, mm ${ }^{2}$ & $13.70 \pm 5.06$ & $14.21 \pm 4.14$ & 0.589 \\
\hline \multicolumn{4}{|l|}{ Lesion segment } \\
\hline EEM CSA, $\mathrm{mm}^{2}$ & $13.00 \pm 5.51$ & $9.43 \pm 3.29$ & 0.000 \\
\hline Lumen CSA, mm ${ }^{2}$ & $1.88 \pm 0.93$ & $1.86 \pm 0.95$ & 0.929 \\
\hline $\mathrm{P}+\mathrm{M}$ CSA, $\mathrm{mm}^{2}$ & $10.96 \pm 5.32$ & $7.57 \pm 3.12$ & 0.000 \\
\hline RI & $1.12 \pm 0.17$ & $0.76 \pm 0.13$ & 0.000 \\
\hline \multicolumn{4}{|l|}{ Distal reference } \\
\hline EEM CSA, $\mathrm{mm}^{2}$ & $11.02 \pm 4.76$ & $10.62 \pm 3.81$ & 0.648 \\
\hline \multicolumn{4}{|l|}{ After the intervention } \\
\hline Minimal stent CSA, $\mathrm{mm}^{2}$ & $7.24 \pm 1.96$ & $7.21 \pm 1.70$ & 0.929 \\
\hline Symmetry index & $1.07 \pm 0.72$ & $1.08 \pm 0.49$ & 0.620 \\
\hline \multicolumn{4}{|l|}{ Follow-up } \\
\hline Lumen volume, $\mathrm{mm}^{3}$ & $160.7 \pm 63.9$ & $171.5 \pm 61.9$ & 0.797 \\
\hline IH volume, $\mathrm{mm}^{3}$ & $33.7 \pm 27.6$ & $20.9 \pm 20.5$ & 0.011 \\
\hline$\% \mathrm{IH}$ & $18.9 \pm 15.6$ & $11.5 \pm 11.3$ & 0.008 \\
\hline
\end{tabular}

$\mathrm{PR} / \mathrm{IR}=$ Positive or intermediate remodeling; $\mathrm{NR}=$ negative remodeling; $\mathrm{P}+\mathrm{M}=$ plaque plus media.

rial remodeling was a significant independent variable for predicting the IH volume in the PES patients $(\mathrm{p}=$ $0.018)$.

\section{Correlation between the RI and $I H$}

The correlation between the RI and the IH volume at follow-up in each patient group is shown in figures 1 and 2. Although there was no correlation between the two parameters in the SES patients $(r=-0.032, \mathrm{p}=0.775)$, a positive correlation was noted in the PES patients $(\mathrm{r}=$ $0.234, \mathrm{p}=0.023$ ).

\section{Discussion}

In the present study population, as in previous studies $[3-5,8,9]$, the baseline remodeling characteristics of the lesion appeared to affect the efficacy after PES implantation, but not after SES implantation. The SES was found to suppress IH effectively, irrespective of any arterial remodeling.

Most previous IVUS studies have shown that positive preinterventional arterial remodeling is related to poor long-term outcomes (more frequent restenosis/target le- 

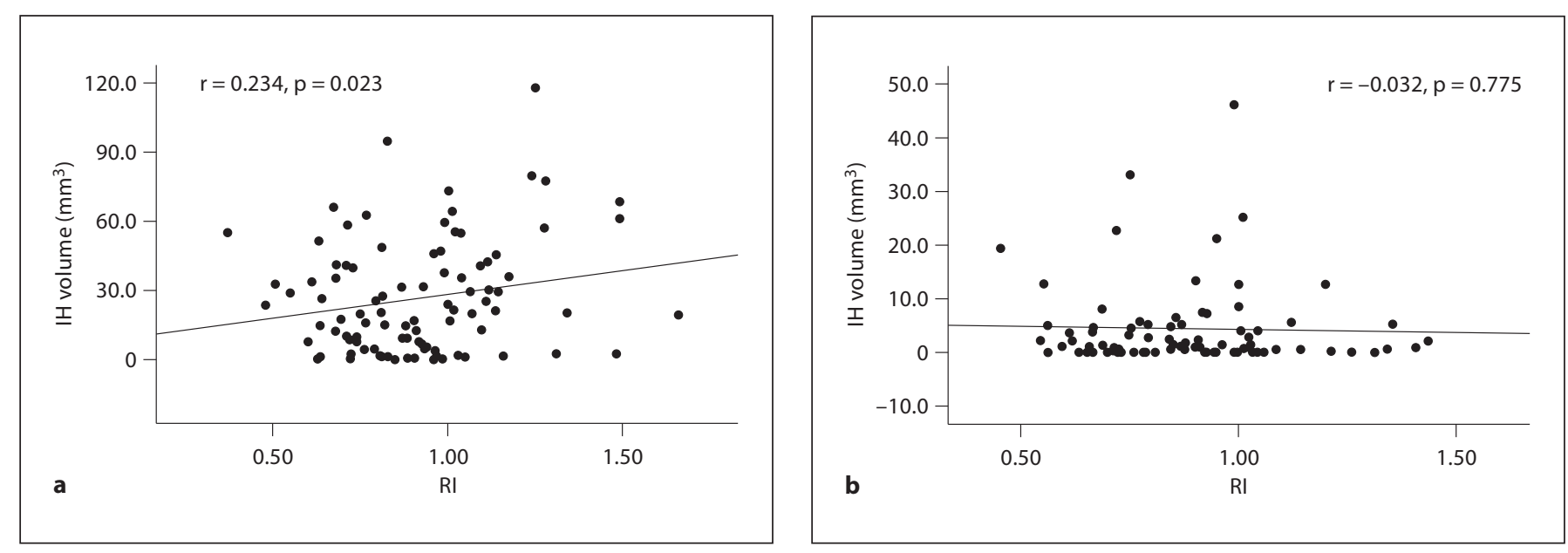

Fig. 1. Correlation between the preinterventional RI and volume of $\mathrm{IH}$ at follow-up in the patients with PES (a) and SES (b) implantations.

sion revascularization or more $\mathrm{IH}$ at follow-up) after bare metal stent implantations $[1,2,5]$, whereas some studies have had controversial results [10]. Moreover, positive remodeling lesions had a larger follow-up IH volume after PES implantation [3, 4]. A possible explanation is that positive remodeling lesions are related to unstable patients who have poor clinical outcomes and also that unstable plaques may be biologically more active [7, 11-13]. Histopathologic studies revealed that positive remodeling is associated with the histological characteristics of inflammation including increased macrophage and matrix metallproteinase expressions which are similar to those unstable and ruptured lesions, suggesting a link between remodeling and inflammation [14-16]. We had reported that an increased inflammatory response, measured by the high-sensitivity C-reactive protein levels, might be associated with an increased IH volume in lesions with positive remodeling after a DES implantation [17]. Mintz et al. [3] reported that preinterventional arterial remodeling, especially negative remodeling, influenced IH suppression after the implantation of non-polymer-encapsulated paclitaxel-coated stents in a small patient population. In their study, the $\% \mathrm{IH}$ was measured to be $18 \pm 13 \%$ for positive remodeling, $23 \pm 22 \%$ for intermediate remodeling and $6 \pm 10 \%$ for negative remodeling, and the $\% \mathrm{IH}$ (overall 16\%) was greater than that for SESs or polymer-based PESs in other studies [18-20]. They inferred that a greater suppression of IH would blunt the relationship between preinterventional arterial remodeling and subsequent $\mathrm{IH}$ accumulation; this assumption is substantiated by the present study. Endo et al. [1] showed that preinterventional remodeling influenced the IH in 113 selected patients treated with a single bare metal stent. In that study, the \% IH was measured to be $51 \pm 19 \%$ for positive remodeling, $42 \pm 18 \%$ for intermediate remodeling, and $35 \pm 20 \%$ for negative remodeling lesions. In the present study, although the overall \%IH (2.8\%) in the SES patients was similar to previous studies $[18,19]$, the overall \%IH (13.8\%) in the PES patients was similar or slightly higher than that in previous studies [21, 22]. On the other hand, Kaneda et al. [8] reported that although the data were analyzed with $2 \mathrm{D}$ IVUS, there was no relationship between the arterial remodeling/plaque burden and the IH after SES implantation, a finding compatible with the present study. The present study suggests that DESs may have a different effect on reducing IH accumulation in lesions with preinterventional positive remodeling characteristics, which may be related to the different properties of the drug and delivery platform. Accordingly, further studies are needed to examine whether the lesion characteristics affect IH after implantation of other kinds of DES.

\section{Study Limitations}

There are several limitations to be mentioned regarding the present study. First, highly selected lesions were included in this study, raising the possibility of selection bias. Therefore, the findings of this study cannot be applied to all coronary lesions. Second, for the assessment of the vascular remodeling, only a single IVUS image in the culprit lesion was assessed. The lesion may feature various geometric differences along its length, so that the 
chosen frame may not be characteristic of certain biological properties of the entire stenosis. Third, 9 months' follow-up duration may not be enough to see subsequent findings or the relationships identified in the present study.

\section{Conclusion}

This prospective observational IVUS study showed that DESs may have a different effect on reducing IH accumulation in lesions with preinterventional positive remodeling characteristics, which may be related to the different properties of the drug and delivery platform.

\section{References}

1 Endo A, Hirayama H, Yoshida O, et al: Arterial remodeling influences the development of intimal hyperplasia after stent implantation. J Am Coll Cardiol 2001;37:70-75.

$\checkmark 2$ Hoffmann R, Mintz GS: Coronary in-stent restenosis - predictors, treatment and prevention. Eur Heart J 2000;21:1739-1749.

-3 Mintz GS, Tinana A, Hong MK, et al: Impact of preinterventional arterial remodeling on neointimal hyperplasia after implantation of (non-polymer-encapsulated) paclitaxelcoated stents: a serial volumetric intravascular ultrasound analysis from the ASian Paclitaxel-Eluting Stent Clinical Trial (ASPECT). Circulation 2003;108:1295-1298.

$\checkmark 4$ Kang WC, Oh KJ, Han SH, et al: Effect of preinterventional arterial remodeling on intimal hyperplasia after implantation of a polymer-based paclitaxel-eluting stent: angiographic and IVUS study. Int J Cardiol 2007;123:50-54.

5 Wexberg P, Gyongyosi M, Sperker W, et al: Pre-existing arterial remodeling is associated with in-hospital and late adverse cardiac events after coronary interventions in patients with stable angina pectoris. J Am Coll Cardiol 2000;36:1860-1869.

6 Okura H, Hayase M, Shimodozono S, et al: Impact of pre-interventional arterial remodeling on subsequent vessel behavior after balloon angioplasty: a serial intravascular ultrasound study. J Am Coll Cardiol 2001;38: 2001-2005.

$\checkmark 7$ Schoenhagen P, Ziada KM, Kapadia SR, et al: Extent and direction of arterial remodeling in stable versus unstable coronary syndromes: an intravascular ultrasound study. Circulation 2000;101:598-603.
-8 Kaneda H, Koizumi T, Ako J, et al: Impact of intravascular ultrasound lesion characteristics on neointimal hyperplasia following sirolimus-eluting stent implantation. Am J Cardiol 2005;96:1237-1241.

-9 Park SJ, Shim WH, Ho DS, et al: A paclitaxeleluting stent for the prevention of coronary restenosis. N Engl J Med 2003;348:15371545.

10 Hong MK, Park SW, Lee CW, et al: Preintervention arterial remodeling as a predictor of intimal hyperplasia after intracoronary stenting: a serial intravascular ultrasound study. Clin Cardiol 2002;25:11-15.

11 Burke AP, Farb A, Malcom GT, et al: Coronary risk factors and plaque morphology in men with coronary disease who died suddenly. N Engl J Med 1997;336:1276-1282.

12 Smits PC, Pasterkamp G, de Jaegere PP, et al: Angioscopic complex lesions are predominantly compensatory enlarged: an angioscopy and intracoronary ultrasound study. Cardiovasc Res 1999;41:458-464.

13 Yamagishi M, Terashima M, Awano K, et al: Morphology of vulnerable coronary plaque: insights from follow-up of patients examined by intravascular ultrasound before an acute coronary syndrome. J Am Coll Cardiol 2000;35:106-111.

14 Burke AP, Kolodgie FD, Farb A, et al: Morphological predictors of arterial remodeling in coronary atherosclerosis. Circulation 2002;105:297-303.

15 Ivan E, Khatri JJ, Johnson C, et al: Expansive arterial remodeling is associated with increased neointimal macrophage foam cell content: the murine model of macrophagerich carotid artery lesions. Circulation 2002 105:2686-2691.
16 Varnava AM, Mills PG, Davies MJ: Relationship between coronary artery remodeling and plaque vulnerability. Circulation 2002; 105:939-943.

17 Kang WC, Ahn TH, Moon CT, et al: Impact of arterial remodeling on high sensitive Creactive protein after a DES implantation. Int J Cardiol DOI: 10.1016/j.ijcard.2009.11.050.

18 Serruys PW, Degertekin M, Tanabe K, et al: Intravascular ultrasound findings in the multicenter, randomized, double-blind RAVEL (RAndomized study with the sirolimus-eluting VElocity balloon-expandable stent in the treatment of patients with de novo native coronary artery Lesions) trial. Circulation 2002;106:798-803.

19 Sonoda S, Morino Y, Ako J, et al: Impact of final stent dimensions on long-term results following sirolimus-eluting stent implantation: serial intravascular ultrasound analysis from the sirius trial. J Am Coll Cardiol 2004; 43:1959-1963.

20 Weissman NJ, Koglin J, Cox DA, et al: Polymer-based paclitaxel-eluting stents reduce in-stent neointimal tissue proliferation: a serial volumetric intravascular ultrasound analysis from the TAXUS-IV trial. J Am Coll Cardiol 2005;45:1201-1205.

21 Aoki J, Colombo A, Dudek D, et al: Peristent remodeling and neointimal suppression 2 years after polymer-based, paclitaxel-eluting stent implantation: insights from serial intravascular ultrasound analysis in the TAXUS II study. Circulation 2005;112:38763883.

22 Stone GW, Ellis SG, Cox DA, et al: A polymer-based, paclitaxel-eluting stent in patients with coronary artery disease. $\mathrm{N}$ Engl J Med 2004;350:221-231. 